\title{
Daytime gigahertz scintillations near magnetic equator: relationship to blanketing sporadic $E$ and gradient-drift instability
}

\author{
Aramesh Seif ${ }^{1} 2^{*}$, Roland T. Tsunoda ${ }^{3}$, Mardina Abdullah ${ }^{1,4}$ and Alina Marie Hasbi ${ }^{1,4}$
}

\begin{abstract}
Observations made in non-equatorial regions appear to support the hypothesis that the daytime scintillation of radio signals at gigahertz $(\mathrm{GHz})$ frequencies is produced by the gradient-drift instability $(\mathrm{GDI})$ in the presence of a blanketing sporadic $E\left(E_{s b}\right)$ layer. However, the only evidence offered, thus far, to validate this notion, has been some observations of $\mathrm{E}_{\mathrm{sb}}$ in the vicinity of $\mathrm{GHz}$ scintillations. A more comprehensive evaluation requires information about electric field, together with the presence of a steep gradient, which is presumed to be that of $\mathrm{E}_{\mathrm{sb}}$. In this regard, the region in the vicinity of the equatorial electrojet (EEJ) appears to be an ideal "laboratory" to conduct such experiments. The dominant driver of electron drift there is the same as that of the EEJ, the vertical polarization electric field, and indications are that the presence of $E_{s b}$ in that vicinity is controlled by a balance in horizontal transport of $E_{s b}$ between the EEJ electric field and the neutral wind, as described in a model by Tsunoda (On blanketing sporadic E and polarization effects near the equatorial electrojet, 2008). In this paper, we present, for the first time, results from a comprehensive study of daytime $\mathrm{GHz}$ scintillations near the magnetic equator. The properties, derived from measurements, are shown, for the first time, to be consistent with a scenario in which $\mathrm{E}_{\mathrm{sb}}$ presence is dictated by the Tsunoda model, and the plasma-density irregularities responsible for $\mathrm{GHz}$ scintillations appear to be produced by the GDI.
\end{abstract}

Keywords: Daytime GHz scintillation, Blanketing sporadic $\mathrm{E}\left(\mathrm{E}_{\mathrm{sb}}\right)$, Magnetic dip equator, Equatorial electrojet (EEJ)

\section{Background}

Amplitude scintillations at gigahertz $(\mathrm{GHz})$ frequencies have been observed during the day and at night. Nevertheless, daytime $\mathrm{GHz}$ scintillation studies attracted as much attention as nighttime scintillation studies, perhaps because daytime scintillation have a relatively lower rate of occurrence and milder nature (Patel et al. 2009). For the most part, scintillations are generally believed to be associated with the $\mathrm{F}$ layer at night and the blanketing sporadic $\mathrm{E}$ $\left(\mathrm{E}_{\mathrm{sb}}\right)$ layer during the day (Kumar et al. 2007; Zou and Wang 2009; Zou 2011; Seif et al. 2012; Alfonsi et al. 2013).

\footnotetext{
* Correspondence: arameshseif@gmail.com

${ }^{1}$ Department of Electrical, Electronics and Systems Engineering, Faculty of Engineering and Built Environment, Universiti Kebangsaan Malaysia, 43600 Selangor, Malaysia

${ }^{2}$ SPACE Research Centre, RMIT University, Melbourne, Victoria, Australia Full list of author information is available at the end of the article
}

The absence of $\mathrm{F}$ layer $\mathrm{GHz}$ scintillations during the day is reasonable; that is, plasma structure does not develop in the $\mathrm{F}$ layer because its development depends on the appearance of polarization electric fields $\left(\mathrm{E}_{\mathrm{p}}\right)$ that are associated with currents in the F layer, and such fields cannot appear during the day in the presence of a highly conducting, solar-produced $\mathrm{E}$ layer. For this reason, daytime scintillations must be associated with irregularities in the E layer. Moreover, irregularities are not usually found in the normal solar-produced $\mathrm{E}$ layer, the contributing factor is likely to be the presence of the $\mathrm{E}_{\mathrm{sb}}$ layer.

The basis for the association of radio scintillations to $\mathrm{E}_{\mathrm{sb}}$ is largely observational. Given that this association appears to be real, researchers have invoked the gradientdrift instability (GDI) (Whitehead 1969; Ecklund et al. 1981; BaiQui et al. 2012; Chatterjee et al. 2013) as the source mechanism. This theory was proposed in the

\section{倠 Springer}


mid-latitude ionosphere, where the inclination (I) of the geomagnetic field (B) is steep enough to produce a thin layer of high plasma density, via the wind-shear theory (Whitehead 1969; Miller and Smith 1975, 1978). If the plasma density is high enough, and the gradient is steep enough, the geometry should be unstable, in the presence of a background neutral wind, to the gradient-drift process. According to the preceding discussion, we would then expect scintillations to occur in the mid-latitude region. In fact, several investigations (Hajkowicz 1977, 1978; Fujita et al. 1978; Sinno and Kan 1980; Ogawa et al. 1989; Hajkowicz and Minakoshi 2003), have shown the existence of a close relationship has been found between midlatitude daytime scintillations and $\mathrm{E}_{\mathrm{sb}}$. In most studies, the GDI is usually mentioned as the likely source mechanism.

Low-latitude observations have also indicated a correlation between the occurrence of daytime scintillation and $E_{\mathrm{sb}}$ (Huang 1978; Patel et al. 2007, 2009). Additionally, a few observations of scintillation in the range of $\mathrm{GHz}$ have been also investigated for low latitudes. For example, Kumar et al. (2007) used radio transmissions from geostationary satellite Intelsat to determine scintillations at $3.925 \mathrm{GHz}$ at Suva, Fiji $\left(18.08^{\circ} \mathrm{S}, 178.3^{\circ} \mathrm{E}\right.$; dip latitude $\left.(\Phi)=22.55^{\circ} \mathrm{S}\right)$. They showed that scintillation was more pronounced during the daytime. Zou and Wang (2009) and Zou (2011) observed daytime GHz scintillation from a station at Guilin, China $\left(25.29^{\circ} \mathrm{N}, 110.33^{\circ} \mathrm{E} ; \Phi=\right.$ $21.57^{\circ} \mathrm{N}$ ). They found a correlation between occurrences of daytime $\mathrm{GHz}$ scintillation and $\mathrm{E}_{\mathrm{sb}}$ as seen from signal-tonoise ratio (SNR) measurement obtained from Constellation Observing System for Meteorology, Ionosphere, and Climate (COSMIC) radio occultation. Recently, Chatterjee et al. (2013) used a Global Navigation Satellite System (GNSS) receiver to observe daytime $\mathrm{GHz}$ scintillation from Raja Peary Mohan College (RPMC), India $\left(22.66^{\circ} \mathrm{N}\right.$, $88.39^{\circ} \mathrm{W} ; \Phi=32.83^{\circ} \mathrm{N}$ ), during the local summer. They found that daytime scintillation may be associated with $\mathrm{E}_{\mathrm{sb}}$ using ionosonde data obtained at Trivandrum $\left(8.73^{\circ}\right.$ $\mathrm{N}, 77.7^{\circ} \mathrm{E} ; \Phi=1.69^{\circ} \mathrm{N}$ ) and mentioned the GDI could be a source mechanism of daytime scintillation.

To date, no comprehensive investigations of equatorial daytime $\mathrm{GHz}$ scintillations have been conducted as thoroughly as they have been at mid and low latitudes. In particular, observations of daytime $\mathrm{GHz}$ scintillation in the vicinity of the dip equator have yet to be reported; these observations are the focus of this paper. However, a few observations in the very high frequency (VHF) and ultra high frequency (UHF) bands have been made from stations in the vicinity of the dip equator (Rastogi et al. 1977; Rastogi and Mullen 1981; Koparkar et al. 1989). In all cases, researchers have attributed the observed daytime scintillations to be associated with $\mathrm{E}_{\mathrm{sb}}$, and GDI is mentioned as the source mechanism.
From our literature review, it is evident that very little is known about the nature of daytime $\mathrm{GHz}$ scintillations in the vicinity of the dip equator. Thus, the observations presented in this paper are important to understanding the detailed properties of daytime $\mathrm{GHz}$ scintillations and their relationship to $E_{s b}$, as well as to interpret the role of GDI on daytime GHz scintillation as a source mechanism, where $B$ has a zero or very small I.

In this paper, we present the characteristics of daytime GHz scintillation using GPS Ionospheric Scintillation and Total Electron Content Monitor (GISTM) systems from two stations in Malaysia: Universiti Kebangsaan Malaysia $(\mathrm{UKM})\left(2.55^{\circ} \mathrm{N}, 101.461^{\circ} \mathrm{E} ; \Phi=5.78^{\circ} \mathrm{S}\right)$ and National Observatory at Langkawi $\left(6.19^{\circ} \mathrm{N}, 99.51^{\circ} \mathrm{E} ; \Phi=1.90^{\circ} \mathrm{S}\right)$. The sites are particularly interesting for their locations in terms of EEJ strength; Langkawi is situated very close to the magnetic dip equator whereas UKM is displaced from the dip equator. These sites offer the opportunity to determine the latitudinal distribution of daytime $\mathrm{GHz}$ scintillation in the vicinity of the dip equator. In this paper, we describe experimental results of the investigation of the properties of daytime $\mathrm{GHz}$ scintillation in the vicinity of the dip equator. This experiment led to a large data set collected over a period of 1 year using two receivers. Our findings are shown to be consistent with the latitudinal boundary of $\mathrm{E}_{\mathrm{sb}}$ proposed by the Tsunoda model (Tsunoda, 2008). We, however, have found that daytime $\mathrm{GHz}$ scintillation can occur very close to the dip equator. In order to interpret how scintillation might be produced over the dip equator, we, therefore, envision a scenario in which $E_{s b}$ can be present at the dip equator when there is no EEJ. We close the paper with a discussion of our key findings, and we clarify the role of GDI as a source mechanism of daytime $\mathrm{GHz}$ scintillation in the vicinity of the dip equator. This mechanism requires irregularities produced by a sufficient gradient in the electron density and electric current flow produced by an electric field or a wind (Fejer and Kelley 1980).

\section{Methods}

\section{Instrumentation and data}

The results presented herein are all derived from measurements made with two GPS receivers. The GSV4004 dual-frequency receiver consists of GISTM systems, which are based upon NovAtel's OEM4 installed at UKM and Langkawi in Malaysia. The primary purpose of GSV4004 receiver is to collect ionospheric scintillation for all visible GPS satellites (up to 11). The GPS receiver is used to determine amplitude scintillation (at a $50 \mathrm{~Hz}$ rate) for each GPS satellite at the L1 $(1.575 \mathrm{GHz})$ frequency. The amplitude scintillation is computed by monitoring the S4 index, which derives from the detrended signal intensity (SI) (Van Dierendonck et al. 1993). The GPS receiver provides continuous amplitude scintillation (S4 
index) every $60 \mathrm{~s}$ (Van Dierendonck et al. 1993). This study is based on the analysis of amplitude scintillation (S4 index) data. The period under investigation ranges from January to December 2011 at UKM and Langkawi.

The total S4 $\left(\mathrm{S}_{4 \mathrm{~T}}\right)$, which includes S4 due to the effects of ambient noise is computed over the same $60 \mathrm{~s}$ interval and is defined as follows (Van Dierendonck et al. 1993):

$$
S_{4 T}=\sqrt{\frac{\left\langle\mathrm{SI}^{2}\right\rangle-\langle\mathrm{SI}\rangle^{2}}{\langle\mathrm{SI}\rangle^{2}}}
$$

where $\langle>$ represents the mean value over $60 \mathrm{~s}$.

The GSV4004 receiver also calculates the correction to the total S4 $\left(S_{4 N_{0}}\right)$, which is the effect of ambient noise over the same $60 \mathrm{~s}$ interval (Van Dierendonck et al. 1993). This calculation can be conducted by estimating the average signal-to-noise density $\left(\mathrm{S} / \mathrm{N}_{0}\right)$ over $60 \mathrm{~s}$ and by using that estimate to predict $S_{4 N_{0}}$ caused by ambient noise, which is given by

$$
S_{4 N 0}=\sqrt{\frac{100}{\left\langle S / N_{0}\right\rangle}\left(1+\frac{500}{19\left\langle S / N_{0}\right\rangle}\right)}
$$

Thus, the corrected value of S4 is calculated by subtracting the square of $S_{4 \mathrm{~N}_{0}}$ value from the square of (1).

$$
S_{4 N 0}=\sqrt{\frac{\left\langle\mathrm{SI}^{2}\right\rangle-\langle\mathrm{SI}\rangle^{2}}{\langle\mathrm{SI}\rangle^{2}}-\frac{100}{\left\langle S / N_{0}\right\rangle}\left(1+\frac{500}{19\left\langle S / N_{0}\right\rangle}\right)}
$$

No scintillation is observed in which the value under the radical might be negative. We remove the effect of ambient noise under scintillation circumstances. Thus, the corrected S4 without the effects of ambient noise can be calculated as follows (Dubey et al. 2006):

$$
S 4=\sqrt{S_{4 T}^{2}-S_{4 N_{0}}^{2}}
$$

In order to account for varying geometrical effects on the measurements made at different elevation angles, the amplitude scintillation index is projected to the vertical according to the formulae described in (Alfonsi et al. 2013). The elevation and azimuth of every GPS satellite signal that is received are recorded every $60 \mathrm{~s}$. We focus our attention on an infinitely thin layer within the $\mathrm{E}$ layer at an altitude of $110 \mathrm{~km}$ above the Earth's surface. The reason is that previous studies (as discussed in "Background" section) have been shown that daytime scintillation and $\mathrm{E}_{\mathrm{sb}}$ are correlated. $E_{s b}$ layer is considered to have the form of a thin sheet in which the electron density is higher than that of the background ionization. These sheets have been observed to occur at altitudes between 90 and $110 \mathrm{~km}$ (Tong et al. 1988; Wu et al. 2005). For this study, we need the nominal ionospheric pierce point (IPP) height to determine the latitude associated with the scintillation. Hence, the height of $110 \mathrm{~km}$ is assumed to be that of the irregularity sheet, where scintillation occurs. The IPP is defined to be the point where an incoming GPS signal ray intersects the ionosphere. By prescribing the altitude of $110 \mathrm{~km}$ for the IPP, the elevation and azimuth of the GPS satellite may then be used to calculate the location of the IPP.

For this study, in order to remove the multipath effect, we have used only the satellite signals that arrive at the receiver with an elevation angle of greater than $15^{\circ}$, and only times of lock greater than $240 \mathrm{~s}$ were considered. Moreover, we have used a multipath elimination technique to distinguish whether the S4 measurements were caused by scintillation or multipath (Van Dierendonck et al. 1993). In fact, the receiver collects raw sigma code/ carrier divergence (difference between code and carrier pseudorange) every second. The average and standard deviation of the sigma code/carrier divergence are then computed every minute in which S4 is calculated. These values are indicative of multipath and can be used to distinguish between S4 due to multipath and S4 due to scintillation. In other words, this elimination process is based upon a comparison of the sigma code/carrier divergence measurement to the S4 measured (Van Dierendonck et al. 1993). This implies that, if the pseudorange error is less than a linear function of S4, the S4 is recognized to be due to scintillation. The reason is that scintillation fading does not cause pseudorange errors (Van Dierendonck et al. 1993). Therefore, we used filtering equation as follows. In other words, if $\delta_{\mathrm{PR}}<0.625, S 4-0.125, S 4 \geq 0.2$, where $\delta_{\mathrm{PR}}$ is sigma pseudorange; $\mathrm{S} 4$ is due to scintillation; otherwise, S4 is due to multipath. This technique has been used to filter out S4 due to multipath from that due to scintillation.

The sigma code-carrier divergence versus $\mathrm{S} 4$ is computed for all the scintillation. To illustrate the effects of multipath on S4, an example of estimated pseudorange errors (code-carrier divergence) is plotted against S4 for the all GPS PRNs as shown in Fig. 1. Figure 1a shows an example of daytime scintillation occurred on 1 March 2011 at UKM. Figure $1 \mathrm{~b}$ shows daytime scintillation on 1 March 2011 at Langkawi. The plot helps discriminate the difference between the effects of multipath and scintillation. The solid line derived from the filtering equation (as mentioned above) was then applied to scintillation days discriminate S4 from multipath. In Fig. 1, the solid line divides the points due to multipath or scintillation. The points that lie above the line are considered as multipath, whereas the points below the line indicate scintillation (Van Dierendonck et al. 1993).

The analysis is further limited to the measurements of daytime amplitude scintillation activity recorded from 06:00 local time (LT) to 18:00 LT (22:00 universal time (UT) to 10:00 UT) only, which is thought to occur for a GPS satellite when $\mathrm{S} 4 \geq 0.2$ for $4 \mathrm{~min}$. Similar to other 


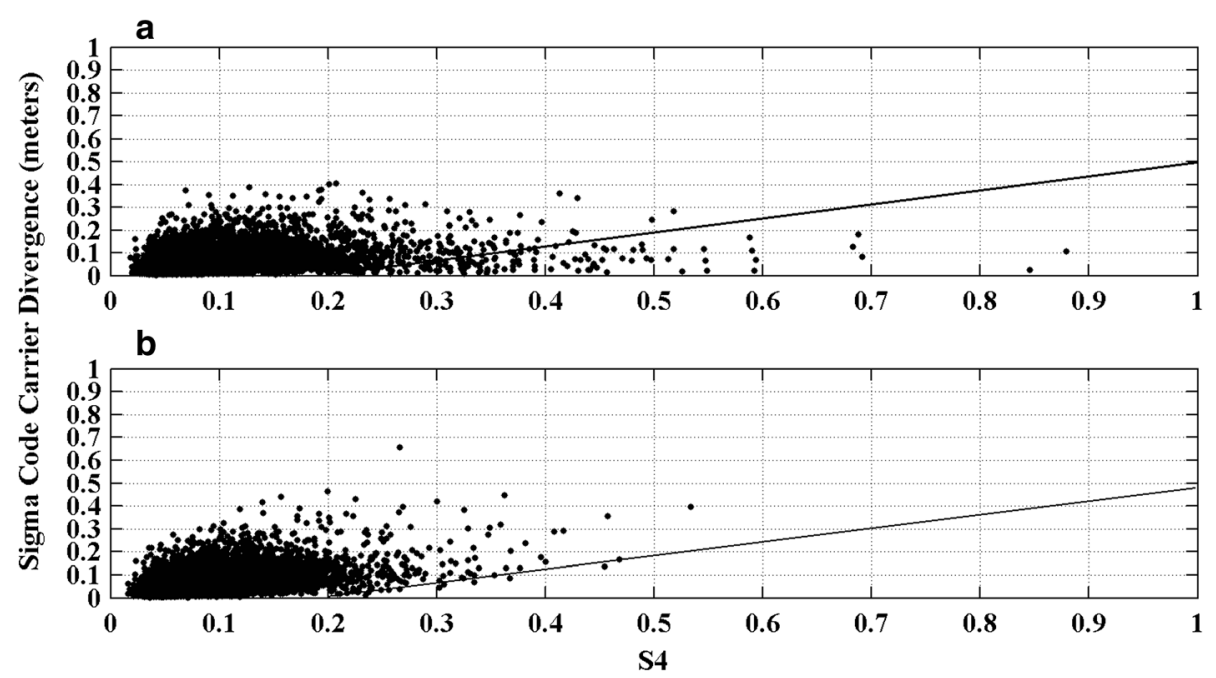

Fig. 1 Multipath technic illustration. Sigma code-carrier divergence versus S4 a daytime GHz scintillation event on 1 March 2011 at UKM and b daytime GHz scintillation event on 1 March 2011 at Langkawi. Everything above the line is likely to be multipath

researchers (e.g., Zou 2011; Tanna et al. 2013), such thresholds are considered as a scintillation event. The intensity of daytime scintillation is classified as negligible $(\mathrm{S} 4<0.2)$, weak $(0.2 \leq \mathrm{S} 4<0.3)$, moderate $(0.3 \leq \mathrm{S} 4<0.4)$, and strong $(\mathrm{S} 4 \geq 0.4)$.

\section{Results and Discussion \\ Experimental results}

Data acquired at UKM and Langkawi in 2011 are analyzed. It should be noted that the observation period January-December 2011 belongs to a period of low solar activity, the daily $10.7-\mathrm{cm}$ solar radio flux (F10.7 index) varied from 71.9 to 113.2 (in units of $10^{22} \mathrm{Wm}^{-2} \mathrm{~Hz}^{-1}$ ), and the sunspot number was in the range of 9.2-63.4. We aim to (1) compare the characteristics of daytime $\mathrm{GHz}$ scintillation at both stations UKM and Langkawi, where Langkawi is very close to the magnetic dip equator and UKM is far away from the magnetic dip equator; (2) investigate the diurnal and seasonal characteristics of daytime $\mathrm{GHz}$ scintillation in the vicinity of the dip equator; (3) determine the latitudinal distribution of daytime $\mathrm{GHz}$ scintillation occurrence and verify whether the distribution is consistent with $\mathrm{E}_{\mathrm{sb}}$ patches according to the Tsunoda model (Tsunoda 2008); and (4) present an interpretation that appears to be consistent with the GDI as the source mechanism of daytime $\mathrm{GHz}$ scintillation.

\section{Comparison of daytime $\mathrm{GHz}$ scintillation occurrences at UKM and Langkawi}

The days and times of scintillation occurrences at UKM and Langkawi in 2011 have been compared to verify (1) whether scintillation was present at both stations, most of the days, and (2) whether scintillation shows any systematic differences in terms of the signal intensity and their durations at each station.

With regard to the first question, the number of days of scintillation observed at both stations was 320 of the 334 days of observation at the UKM station compared with 65 of the 350 days of observation at the Langkawi station. In other words, the occurrence of scintillation was found to be more frequent over UKM than over Langkawi. This leads to the conclusion that irregularities are not uniformly distributed over these two stations.

Analysis has been made in order to determine the intensity levels of scintillation and their duration at each station. For this purpose, day-to-day amplitude scintillation (S4 index) for all PRNs was studied for each month throughout the observation period. Figure 2 shows typical examples of the different levels of the $\mathrm{S} 4$ index $(\mathrm{S} 4=0.2$, 0.3 , and 0.4$)$ plotted against the LT $(\mathrm{LT}=\mathrm{UT}+8)$ for both stations. Strong scintillations were observed more at UKM located away from the dip equator, with S4 indices exceeding 0.5. By contrast, strong scintillations were rarely observed at Langkawi (near the dip equator) as the S4 indices were predominantly lower than 0.4. Scintillations at the dip equator are therefore drastically decreased.

Furthermore, these examples show that daytime $\mathrm{GHz}$ scintillation occurrences are intermittent, and their durations are short-lived (this will be discussed in "Comparison of daytime $\mathrm{GHz}$ scintillation occurrences at UKM and Langkawi" section), which is more evident in the Langkawi observations. From these properties, researchers have suggested that the scintillation-producing irregularities are likely produced by GDI, which requires a steep gradient associated with the background plasma-density profile, and a current driven by a neutral wind (Fejer and Kelley 1980; Whitehead 1989). In this regard, Basu et al. (1977) 

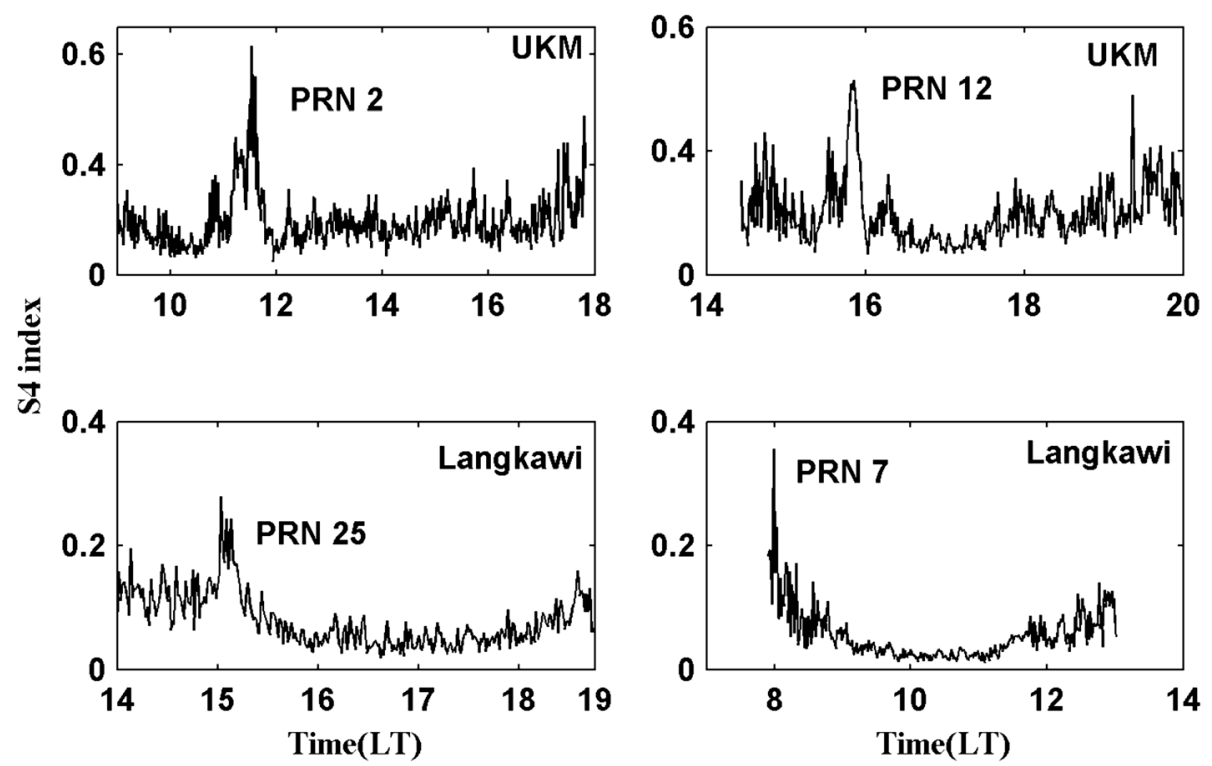

Fig. 2 Comparison of S4 index between UKM and Langkawi stations

have compared VHF scintillation at the dip equator with $50-\mathrm{MHz}$ radar backscatter. They found that scintillation turned on and off in time with the so-called type II echoes, which are produced by the GDI. Similar result has been obtained by Rastogi (1983) who showed that strong VHF scintillation was related to $\mathrm{E}_{\mathrm{sb}}$ over the dip equator; scintillation was weak in the absence of $\mathrm{E}_{\mathrm{sb}}$.

GDI is the mechanism of irregularities formation in plasma patches presented in the equatorial ionospheric $\mathrm{E}$ layer. Several researchers have been discussed the application of the GDI in order to explain the generation of $\mathrm{E}_{\mathrm{sb}}$ layer irregularities (Whitehead 1971, 1989; Fejer and Kelley 1980; Ogawa et al. 1989). The formulation of the GDI by Fejer et al. (1975) clearly shows that the GDI only needs a nonzero plasma drift and a strong plasma density gradient in order to operate. This implies that GDI can operate under weak electric field and low-electron-drift conditions. In other words, the GDI operates in plasma with a gradient in ionization density and with different electron and ion drifts perpendicular to the density gradient (Fejer and Kelley 1980). Furthermore, near the magnetic dip equator, Reddy and Devasia (1977) observed the gradient instability using VHF radar. Hence, the condition required for GDI is likely to be the steep gradient and electric field, which are crucial driving force for such instability.

Further analysis was conducted to determine when and where daytime scintillation occurs at each station and whether the occurrence of scintillation is consistent with the appearance of $E_{s b}$ fulfilling all the requirements for GDI to occur.
Characteristics of daytime $\mathrm{GHz}$ scintillation in the vicinity of the dip equator

\section{Diurnal and seasonal variation}

To investigate whether scintillation has simultaneity or any systematic time difference to $E_{\mathrm{sb}}$ appearances, the diurnal variations of scintillation were studied. To identify the diurnal and seasonal variations of daytime scintillation (between 06:00 LT and 18:00 LT), the amplitude scintillation activities are categorized into three groups of seasons, namely, summer (May, June, July, and August), winter (November, December, January, and February), and equinox (September, October, March, and April).

Figure 3 shows the percentage of occurrence of scintillation, which is sorted by seasons to characterize daytime scintillation. The solid and dashed lines show the percentage of scintillation occurrences for UKM and Langkawi, respectively. The occurrence of scintillation is computed by dividing the number of scintillation events (S4 index above threshold) with the total number of days of available data. The diurnal variation of scintillation at both UKM and Langkawi stations is characterized by three common features: (1) a prominent maximum in the late afternoon, (2) peaks in the morning, around noon, and evening during the equinox, and (3) a peak at 11:00 LT during the summer.

Additional features to be noted from Fig. 3 are the following: (1) as mentioned in "Comparison of daytime $\mathrm{GHz}$ scintillation occurrences at UKM and Langkawi" section, scintillation drastically decreased at Langkawi situated very close to the dip equator. This finding is particularly evident in this figure during all seasons, and (2) at UKM, 


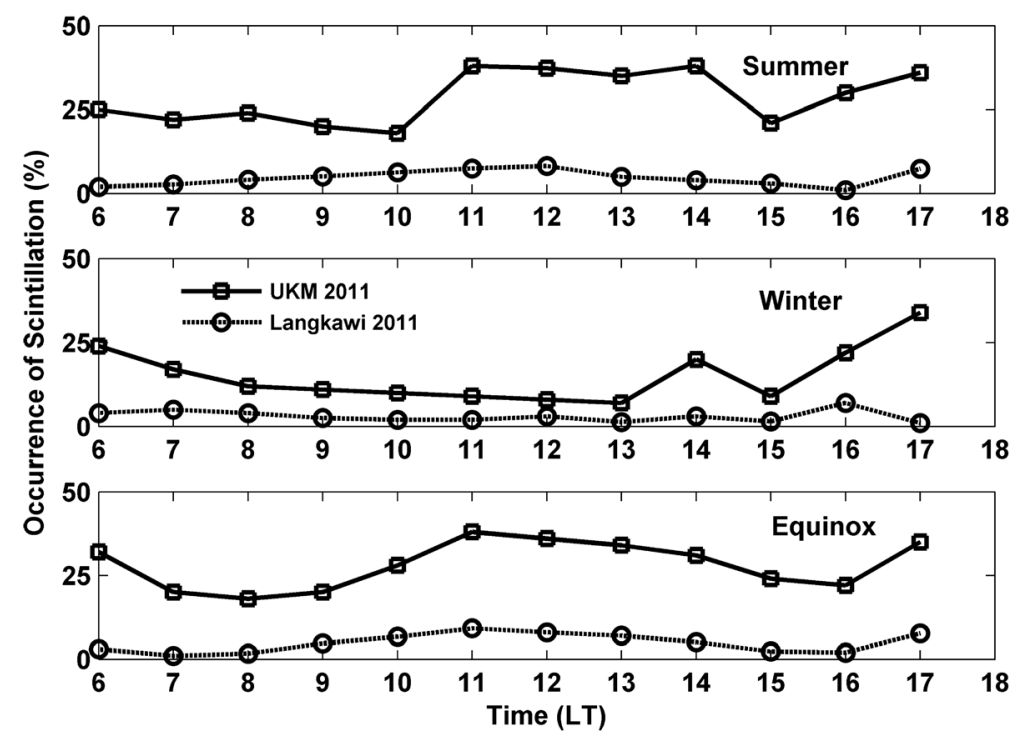

Fig. 3 Diurnal percentage of occurrence of daytime GHz scintillation at UKM and Langkawi in 2011

the percentage of occurrence of scintillation shows a morning peak during winter and equinox.

The finding that the occurrence of daytime scintillation in the late afternoon is maximum suggests that scintillation may be associated with the occurrence of $\mathrm{E}_{\mathrm{sb}}$. There is evidence that the diurnal characteristics of $E_{s b}$ showed a prominent maximum in the late afternoon in the vicinity of the dip equator (Bhargava and Subrahmanyan 1964; Reddy and Devasia 1973; Chandra and Rastogi 1975; Devasia 1976). For example, Chandra and Rastogi (1975) who used ionograms obtained at Kodaikanal $\left(\Phi=3.5^{\circ} \mathrm{N}\right)$ showed the equatorial $\mathrm{E}_{\mathrm{sb}}$ has a major peak around 17:00 LT. This finding is consistent with the diurnal occurrence of scintillation observed in all seasons, which suggests that is associated with the presence of $\mathrm{E}_{\mathrm{sb}}$. Furthermore, it is possible that the scintillation events observed in the late afternoon sector could be due to plasma irregularities in the F-region (e.g., Chatterjee et al. 2014); however, post sunset F-region scintillations are normally observed after 19:00 LT (Somayajulu et al. 1984; Gwal et al. 2004; Carter et al. 2013; Narayanan et al. 2014). Therefore, it is unlikely that the late-afternoon GPS scintillation events analyzed here ( 17:00 LT) are due to F-region plasma irregularities. Ultimately, future research would greatly benefit from supporting observations (e.g., ionosonde) of common scattering volumes with the GPS scintillation detections. On the other hand, Rangarajan and Arora (1980) examined the characteristics of EEJ as a function of local time in the Indian region and found two peaks with the primary one centered at 16:00 LT to 17:00 LT and the other one in the morning. This suggests a possible correlation between the EEJ appearance and scintillation occurrences in the morning and at 16:00 LT to 17:00 LT during all seasons.

At both stations, during the equinox and summer, the percentage of occurrence of scintillation shows a gradual increase from 10:00 LT to 11:00 LT with a maximum peak at 11:00 LT, particularly during the summer at Langkawi. This also suggests that occurrence of scintillation is consistent with the enhancement of EEJ. A typical diurnal profile for EEJ shows a peak strength of EEJ at time of approximately noon (i.e., Chandrasekhar et al. (2014)). In this manner, Alken and Maus (2007) proposed an empirical model of EEJ climatological mean and day-to-day variability as a function of longitude, local time, season, and solar flux. They showed the EEJ peak is significantly strong around local noon. Anderson et al. (2009) showed that during the equinox and summer in the Philippines, India, and Indonesia sectors, the average vertical daytime $\mathbf{E} \times \mathbf{B}$ drift velocity is maximum between 10:00 LT and 11:00 LT. Moreover, they showed that $\mathbf{E} \times \mathbf{B}$ drift velocity gradually increases from 10:00 LT to 13:00 LT in Indonesia during the summer. Therefore, we can expect the enhancement of EEJ between 10:00 LT and 12:00 LT over UKM and Langkawi during the equinox and summer.

As mentioned earlier, the GDI could cause irregularities on $E_{s b}$ patches when all the required conditions are met. This result is also consistent with that reported by Fujita et al. (1978), which indicates that the strong appearance of the $\mathrm{E}_{\mathrm{sb}}$ layer in mid-latitude station at Kokobunji $\left(35.7^{\circ} \mathrm{N}, 139.5^{\circ} \mathrm{E} ; \Phi=29.47^{\circ} \mathrm{N}\right)$ from $10: 45 \mathrm{LT}$ to $11: 30$ LT in July is associated with daytime $\mathrm{GHz}$ scintillation. They suggested that the small irregularities embedded around a large-scale electron density moving within the E 


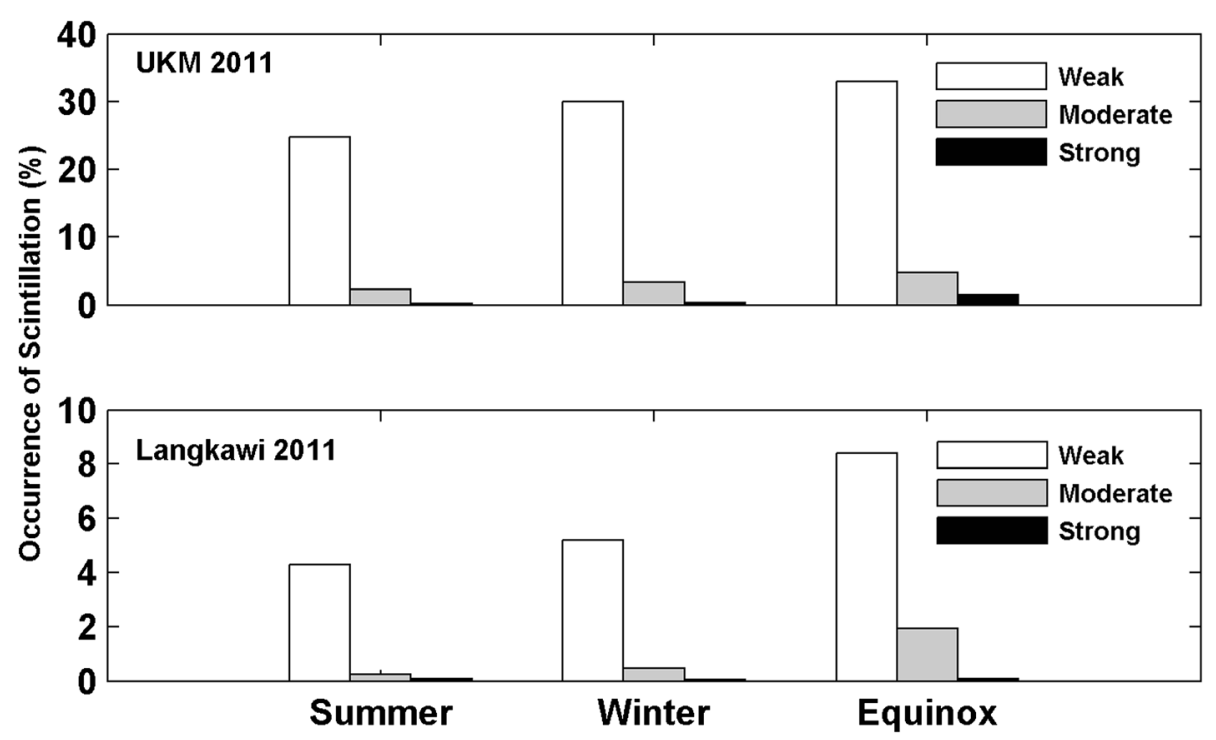

Fig. 4 Seasonal percentage occurrence of daytime scintillation (S4 index) at UKM and Langkawi in 2011

layer across the propagation path may be responsible for the $\mathrm{GHz}$ scintillation.

Figure 4 shows the percentage occurrence of scintillation, which is sorted by seasons in order to examine the seasonal behavior of daytime scintillations under different levels of activities (weak, moderate, and strong) at UKM and Langkawi in 2011.

The most significant fact to be noted in Fig. 4 is that the scintillation (weak, moderate, and strong) that occurred at both UKM and Langkawi exhibits a peak at the equinox and a minimum in the summer, particularly in the Langkawi results. However, at UKM, the maximum occurrence of scintillation in the equinox is not much higher than that during the winter.

In fact, the finding that daytime scintillations most frequently occur during the equinox is consistent with the enhancement of EEJ. Evidence for enhancement of EEJ during the equinox have been presented, e.g., by Alken and Maus (2007) and Anderson et al. (2009). In this manner, Tarpley (1973) explains the enhancement of EEJ in terms of seasonal shift of solar quiet (Sq) foci. He showed that the foci of the Sq current system shift toward the equator during the equinox, which increases the intensity of EEJ. In addition, Chapman and Raja Rao (1965) examined the characteristics of EEJ at two stations at the dip equator: one in India (Trivandrum, $\Phi=0.6^{\circ} \mathrm{S}$ ) and the other in the Pacific region (Koror, $\Phi=0^{\circ}$ ). They found a seasonal dependence of EEJ and Sq, where both are maximum during equinox months. Yacob (1966) obtained similar results, that is, a similar enhancement of EEJ during equinoxes in five low-latitude stations [Koror $\left(\Phi=0^{\circ}\right)$, Trivandrum $\left(\Phi=0.6^{\circ} \mathrm{S}\right)$, Addis Ababa $\left(\Phi=1^{\circ} \mathrm{S}\right)$, Yauca $\left(\Phi=4.4^{\circ} \mathrm{S}\right)$, and Ibadan $\left(\Phi=6.2^{\circ} \mathrm{S}\right)$ ]. Thus, we can expect that the intensity of EEJ is maximum around the equinox in the vicinity of the dip equator at the UKM and Langkawi stations in Malaysia, where the strong electrojet is presumably produced by vertical $E_{p}$ in the EEJ that is maximum during the equinox. In other words, the $\mathrm{E}_{\mathrm{sb}}$ is presumed to provide the exceptionally steep gradient, which is evident as shown by Oyinloye model (1971). He shows the seasonal dependence of $\mathrm{E}_{\mathrm{sb}}$ in the vicinity of the dip equator is maximum during equinox.

Furthermore, the vertical $E_{p}$, which is a dominant component of GDI that operates in the vicinity of the dip equator, is greatly intensified during the equinox. Therefore, the GDI would be driven by the same vertical $E_{p}$ in the EEJ, which leads to increased scintillation.

\section{Distribution of daytime $\mathrm{GHz}$ Scintillation in the vicinity of magnetic dip equator}

To determine where daytime scintillation occurs in the vicinity of the dip equator, we present the geographic distribution of daytime scintillation in Figs. 5, 6, and 7.

Figure 5 shows the geographical distribution of scintillation for three ranges of S4 indices measured for all satellites received during 1 year at UKM and Langkawi in 2011. The locations correspond to their IPPs for an altitude of $110 \mathrm{~km}$. Two sets of colors are used: cool set (blue, magenta, and dark red) for Langkawi and warm set (green, yellow, and red) for UKM. The curved, light blue, and gray bands indicate the IPP tracks from various GPS satellites, for which S4 is negligible. The locations of the two stations are shown by triangles. Figures 6 and 7 show locations with moderate and strong scintillation, respectively.

In Figs. 5, 6, and 7, the following points can be noted: 


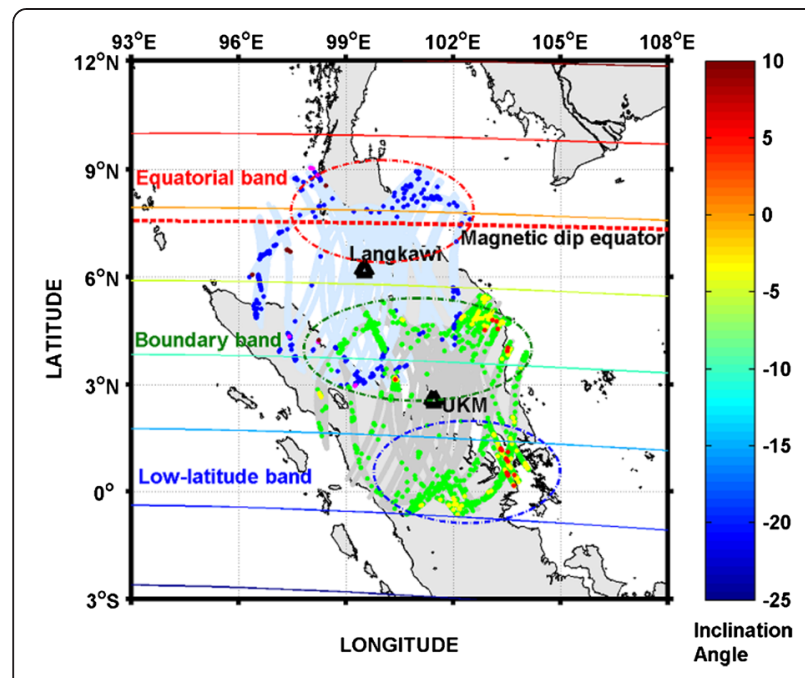

Fig. 5 Geographic distribution of daytime scintillation events ( 44 index) at different levels measured at all GPS satellites observed at UKM and Langkawi from January to December 2011 over Malaysia. The levels of scintillation intensity at UKM are coded for $\$ 4 \geq 0.2$ (green), $\$ 4 \geq 0.3$ (yellow), and $\$ 4 \geq 0.4$ (red), while those at Langkawi are coded as $\$ 4 \geq$ 0.2 (blue), $\$ 4 \geq 0.3$ (magenta), and $\$ 4 \geq 0.4$ (dark red). The red dashed line shows the location of the magnetic dip equator. The contour plots of I are also displayed

First, as stated previously, daytime $\mathrm{GHz}$ scintillations occur frequently over UKM and Langkawi, where satellite elevation angles are low. This finding is consistent with the idea that scintillation-producing irregularities are embedded in a relatively thin layer, and longer path lengths through irregularities are necessary to produce significant scintillations. This need for low elevation angles is also consistent with the idea that $E_{\mathrm{sb}}$ layers are

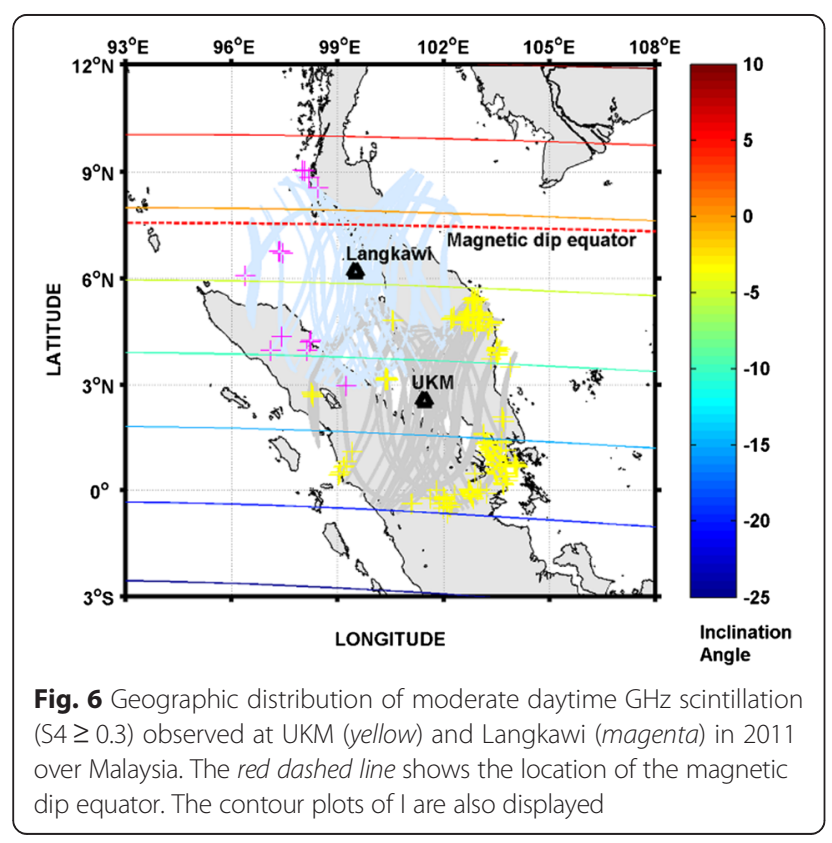

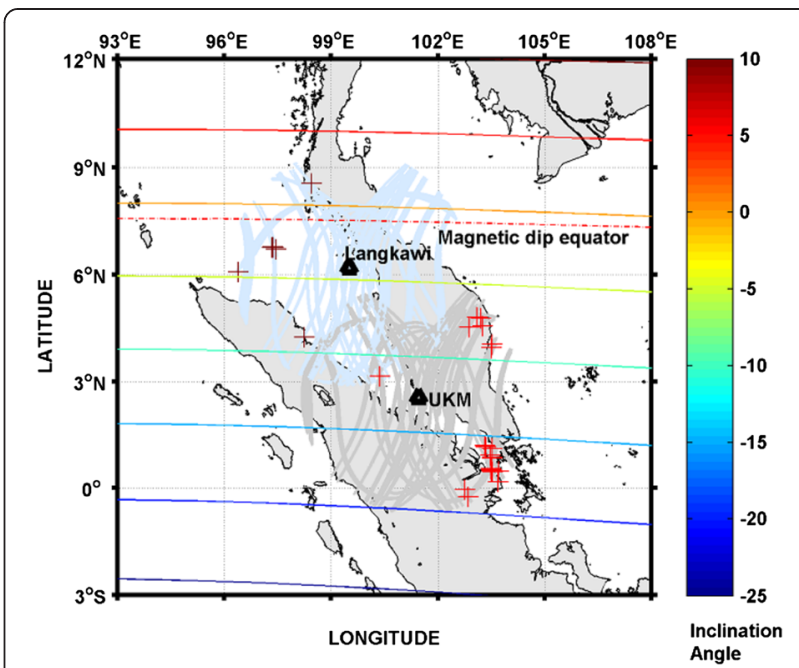

Fig. 7 Geographic distribution of strong daytime $\mathrm{GHz}$ scintillation ( $\$ 4 \geq 0.4$ ) observed at UKM (red asset) and Langkawi (dark red asset) in 2011 over Malaysia. The red dashed line shows the location of the magnetic dip equator. The contour plots of I are also displayed

involved. In this regard, Zeng and Sokolovskiy (2010) used GPS radio occultation (RO) and concluded that the scintillations resulting from Es were a result of wave interference caused by defocusing of the GPS signal within the Es cloud, where this mechanism works for low elevation angles.

Second, from Figs. 6 and 7, which correspond to the location of moderate and strong daytime scintillation, respectively, it is revealed that the moderate and strong daytime $\mathrm{GHz}$ scintillations in the vicinity of the dip equator tend to occur away from the dip equator. In other words, the intensity of scintillations increases with distance from the magnetic dip equator because of the presence of largescale irregularities embedded in the $\mathrm{E}_{\mathrm{sb}}$ layer.

Third, daytime $\mathrm{GHz}$ scintillation decreases drastically very close to the magnetic dip equator. That is, scintillations at the magnetic dip equator have predominantly S4 indices lower than 0.4 (as shown as a blue dot in Fig. 5), whereas the scintillations at UKM exceed $\mathrm{S} 4=0.4$. This difference is shown in the comparison plot (Fig. 2). This finding is also evident in the diurnal and seasonal plots (Figs. 3 and 4). In other words, scintillation occurrence appears to be more frequent and stronger at UKM than at Langkawi. This result suggests latitudinal dependence of daytime scintillation.

According to the Tsunoda model (Tsunoda 2008), the distribution of scintillation in terms of latitude is confined within three latitudinal bands of $\mathrm{E}_{\mathrm{sb}}$, which are the (1) equatorial band, (2) boundary band, and (3) low-latitude band (as illustrated in Fig. 5). In Fig. 5, the two black lines are the approximate latitudes for the equatorward boundaries for $\mathrm{E}_{\mathrm{sb}}\left(\mathrm{EBE}_{\mathrm{sb}}\right)$, according to Oyinloye (1971). This is the average boundary, and they presumably are the 
average locations for the equatorward boundary for the metallic ion streams (MIS) described in Tsunoda (2008). By drawing these lines, we associated the three latitudinal bands of $E_{s b}$ with scintillation (as mentioned above). We will discuss each of these bands in terms of the strength of the EEJ (see "Distribution of daytime GHz scintillation in the vicinity of magnetic dip equator" section).

From Fig. 5, daytime GHz scintillation observed in the northern part of the Langkawi station is consistent with the equatorial band of $E_{s b}$. The scintillation observed between the two stations could be the equatorward boundary of the MIS. By contrast, the scintillation that occurred in the southern UKM coverage region coincides with the low-latitude $E_{s b}$ band. Therefore, scintillation is associated with $\mathrm{E}_{\mathrm{sb}}$, which is in accordance with the Tsunoda model (Tsunoda 2008). This result is also consistent with that obtained by Oyinloye (1971), which indicated $\mathrm{E}_{\mathrm{sb}}$ dependence as a function of $\mathrm{I}$ in the vicinity of the dip equator. He showed that there is a high occurrence rate for $\mathrm{E}_{\mathrm{sb}}$ (15 to $27 \%$ ), where $|\mathrm{I}| \approx 8^{\circ}$. For further details Oyinloye model (Oyinloye 1971) on the occurrence of $E_{s b}$ on the different $I$, the reader is referred to Fig. 1 page 2 of Tsunoda (2008). The presences of these bands are suggestive that the electric field strength in the EEJ may affect the scintillation strength. This will be discussed in "Summary and discussions" section.

\section{Summary and discussions}

This paper concentrated on some of the unique characteristics of the daytime $\mathrm{GHz}$ scintillation in the vicinity of the dip equator in Malaysia, where little or no previous information existed and where the new results have obvious utility for understanding the features of daytime $\mathrm{GHz}$ scintillation and their relationship to the $\mathrm{E}_{\mathrm{sb}}$. We have found, for the first time, that daytime $\mathrm{GHz}$ scintillation does occur very close to the dip equator, where it is not expected based on prevailing models. Therefore, in order to make it clear, we provide a consistent interpretation for these observations. The interpretations require two parts: (1) the Tsunoda model (Tsunoda 2008) and (2) the new interpretation, which is an explanation of how scintillation might be produced very close to the dip equator. Finally, from the comprehensive study of the properties of daytime $\mathrm{GHz}$ scintillation in the vicinity of the dip equator, we have extracted three key findings, which are discussed separately in the following subsections.

\section{Tsunoda model}

Tsunoda model (Tsunoda 2008) discussed how the $\mathrm{E}_{\mathrm{sb}}$ is transported toward the dip equator but is stopped from further advancement to the dip equator. We use this model for interpretation of scintillations that occur in the vicinity of the dip equator.

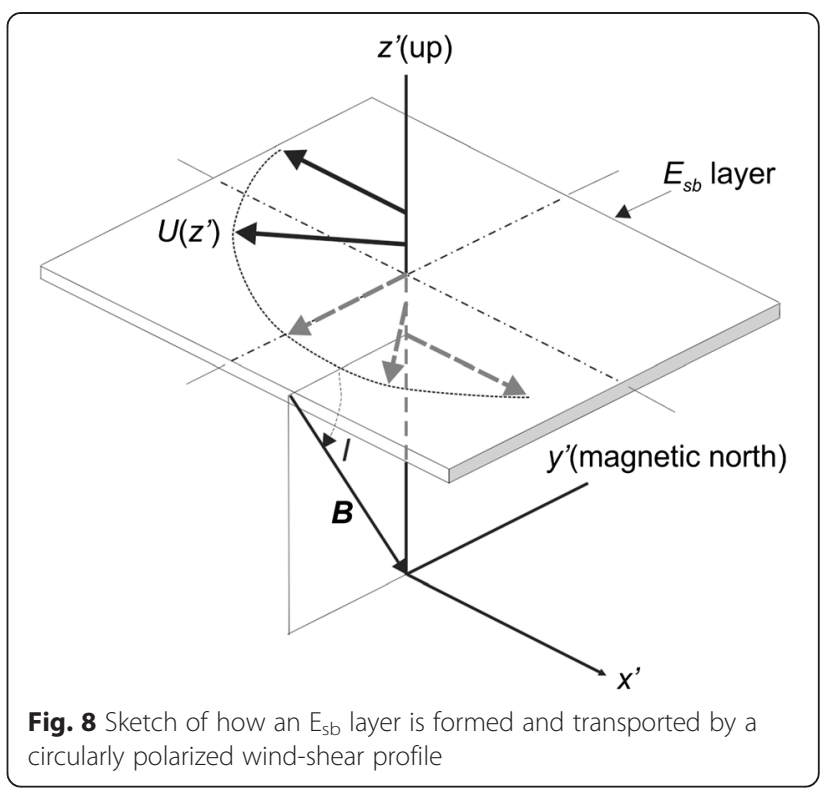

The elements of the Tsunoda model (Tsunoda 2008) that pertain to the interpretation of scintillations that occur in the vicinity of the dip equator can be described with the assistance of the sketch presented in Fig. 8. According to this model, at low latitudes, an $\mathrm{E}_{\mathrm{sb}}$ patch can be expected to approach the EEJ region, where it will encounter the influence of the $E_{p}$ that drives the EEJ. Hence, the anticorrelation between $\mathrm{E}_{\mathrm{sb}}$ over the dip equator and $\mathrm{E}_{\mathrm{p}}$ can be explained by this model.

\section{New interpretation}

According to the Tsunoda model (Tsunoda 2008), $\mathrm{E}_{\mathrm{sb}}$ patch is stopped from further advancement to the dip equator by the presence of the vertical $E_{p}$ that drives the EEJ. Therefore, in the absence of $\mathrm{E}_{\mathrm{sb}}$ over the dip equator, we would expect an absence of scintillations over the dip equator.

We, however, have found that scintillation is observed over the dip equator and that it appears to be rare. We shall address this problem with this new interpretation. In fact, the new interpretation shows how $E_{\mathrm{sb}}$ patches can further advance to the dip equator and explains how scintillation could occur over the dip equator.

Therefore, in order to explain the observed occurrence of scintillations over the dip equator, another element of the Tsunoda model (Tsunoda 2008) is clearly needed (these occurrences, of course, should be relatively rare). Keeping in mind that the $U$ profile is produced by the solar tide, we should expect an associated, downward phase velocity. In other words, the wind-shear node should move downward in altitude with time. Given enough time, the $E_{\mathrm{sb}}$ patch should be transported to an altitude, where the ions become unmagnetized, which means that the $\mathrm{E}_{\mathrm{sb}}$ patch will no longer be transported vertically. If this 
happens in the vicinity of the dip equator, we envision that the $E_{s b}$ patch will be left there, despite any recovery in strength of the $E_{p}$ associated with the EEJ. The return of the $E_{p}$, together with the presence of $E_{s b}$ over the dip equator, is envisioned to lead to irregularity generation by GDI. The reason is that the Hall current will be driven by $E_{p}$, and the $\mathrm{E}_{\mathrm{sb}}$ can provide the gradient needed for irregularity generation. Hence, we envision that scintillation over the dip equator could occur after the recovery of the EEJ from quiet conditions. This will be discussed in "Comparison of daytime $\mathrm{GHz}$ scintillation occurrences at UKM and Langkawi" section.

Three key findings coming out from our study can be discussed as follows:

\section{Comparison of daytime $\mathrm{GHz}$ scintillation occurrences at UKM and Langkawi}

Occurrences of daytime $\mathrm{GHz}$ scintillation at the dip equator are intermittent and their durations are short-lived

We have shown that daytime $\mathrm{GHz}$ scintillation decreases drastically at the dip equator (see Fig. 5). Moreover, our observations show that the occurrences of daytime $\mathrm{GHz}$ scintillation at the dip equator are intermittent and their durations are short-lived (see "Comparison of daytime $\mathrm{GHz}$ scintillation occurrences at UKM and Langkawi" section). In fact, this finding can be explained in terms of $E_{s b}$ appearances. According to the wind-shear theory, the $\mathrm{E}_{\mathrm{sb}}$ layer is commonly observed at temperate latitudes; nevertheless, this mechanism fails to operate at the dip equator (Axford 1961; Whitehead 1966, 1969; Axford and Cunnold 1966). The reason is that the electrons are forced to move along the north-south line running parallel to the Earth's magnetic field and the polarization is fixed between positive ions and electrons. The implication is that intense $E_{s b}$ layers will sometimes form near the magnetic dip equator (as described in "New interpretation" section). Chimonas and Axford (1968) pointed out that at the dip equator, owing to the downward phase of velocity of gravity waves causing the shear, the ionization itself may be transported downward, which is called the corkscreweffect mechanism. According to the new interpretation, this could mean that the $E_{s b}$ patches would then sometimes occur under special circumstances. Such a special situation arises when the electric field becomes zero. That is, we can assume a circularly polarized wind in the $\mathrm{E}$ region, driven by tides. The zonal wind shear produces the convergence of metallic ions to an altitude where the upward and downward forces cancel. There, in the absence of an electric field, the wind will transport the $\mathrm{E}_{\mathrm{sb}}$ sheet equatorward. The Tsunoda model (Tsunoda 2008) is concerned with the latitudinal transport, when a poleward and upward electric field is encountered. The field is associated with the EEJ. The flow of $E_{s b}$ becomes purely zonal, at the latitude where the electric field displaces the $E_{s b}$ to an altitude where the wind is blowing westward. When the electric field weakens, the latitude where zonal flow occurs will shift equatorward.

Another point that is important to note is the tidal wind that is transporting the $\mathrm{E}_{\mathrm{sb}}$ sheet equatorward, or zonally, has a phase velocity, which is directed downward. This means that without the presence of the electric field, the wind-shear node where the $E_{\mathrm{sb}}$ sheet is located will move downward. If downward transport continues, the $E_{s b}$ sheet will reach an altitude where the ion motion is dominated by collisions with the neutrals at these altitudes. In other words, the ions become unmagnetized and $\mathbf{U} \times \mathbf{B}$ is no longer meaningful. When the wind-shear node reaches this altitude, the $E_{s b}$ sheet will no longer follow that node. Hence, it is released at that altitude. As mentioned above, Chimonas and Axford (1968) called this the corkscrew effect and the $E_{\mathrm{sb}}$ patch is dumped at an altitude that is probably close to $90-95 \mathrm{~km}$. However, the electrons remain magnetized. The movement of the electrons relative to the ions provides the current that drives the GDI. Once the $\mathrm{E}_{\mathrm{sb}}$ is dumped, it will no longer be pushed out of the EEJ region by the $E_{p}$. At the same time, the electric field and $E_{s b}$ should be able to produce scintillation via GDI. Therefore, the $\mathrm{E}_{\mathrm{sb}}$ layer can be dumped at low altitude and can still produce the gradient necessary for the GDI.

One possible interpretation is that there could be patches of $E_{s b}$ that have penetrated near to the dip equator and been left there. Therefore, scintillations could still be associated with this $E_{\mathrm{sb}}$ patch and GDI could be the mechanism that causes daytime $\mathrm{GHz}$ scintillation at the dip equator.

\section{Seasonal dependence}

We have shown seasonal dependence of daytime $\mathrm{GHz}$ scintillation with a maximum during equinox months and a minimum during summer. This suggests scintillation is consistent with the enhancement of EEJ and the presence of vertical steep gradients produced by $E_{s b}$ during equinox months in the vicinity of the dip equator as shown by Oyinloye (1971). Therefore, the GDI would be driven by the same vertical $E_{p}$ in the EEJ, which leads to increased scintillation.

\section{Distribution of daytime $\mathrm{GHz}$ scintillation in the vicinity of magnetic dip equator}

As mentioned earlier, the distribution of daytime $\mathrm{GHz}$ scintillation could be explained in the presence of $E_{s b}$ in terms of EEJ strength. We divide the discussion into three subsections according to the bands of $E_{s b}$ as defined in the Tsunoda model (Tsunoda 2008). 


\section{Daytime GHz scintillation association with the low-latitude band of $E_{s b}$}

The scintillation that occurred in the southern UKM region is consistent with the low-latitude $\mathrm{E}_{\mathrm{sb}}$ band. In fact, at lower altitudes, an $\mathrm{E}_{\mathrm{sb}}$ layer would form by the windshear theory and, in this case, the ions would be flowing southward in the $E_{s b}$ layer. The ion motion in an $E_{s b}$ layer must, therefore, rotate from a westward direction at higher altitudes to a southward direction at lower altitudes as the $E_{s b}$ layer is transported downward by the tidal wind system (Tsunoda 2008). At low altitudes, the ions are unmagnetized and move only horizontally with neutral wind $(\mathbf{U})$, which itself is horizontal. Thus, in the presence of $\mathbf{U}$, an $E_{s b}$ layer forms at the zonal wind-shear node and drifts with $\mathbf{U}$, which is equatorward at the shear node. According to the Tsunoda model (Tsunoda 2008), this description of neutral dynamics and low-latitude $E_{s b}$ is consistent with observations of scintillation at a lowlatitude band of $E_{s b}$. The GDI would then be driven by the same $\mathbf{U}$, which should lead to stronger scintillation.

\section{Daytime GHz scintillation association with boundary band of $E_{s b}$}

The scintillation observed between the two stations could be the equatorward boundary of MIS. According to the Tsunoda model (Tsunoda 2008), an implication could be that the metallic ions in the $\mathrm{E}_{\mathrm{sb}}$ patch end up in a strip, which is narrow and aligned along the equatorward boundary for $\mathrm{E}_{\mathrm{sb}}\left(\mathrm{EBE}_{\mathrm{sb}}\right)$. However, there is no electrojetlike current flow within the MIS, because metallic ions and electrons move westward together. Hence, the number density of metallic ions $\left(\mathrm{n}_{\mathrm{mi}}\right)$ in the MIS should increase. This result is consistent with observations of $\mathrm{GHz}$ scintillation at an $\mathrm{EBE}_{\mathrm{sb}}$ band of $\mathrm{E}_{\mathrm{sb}}$. The equatorward transport of $E_{s b}$ is diverted into a zonal flow, where there exists the possibility that the metallic ions that constitute the $\mathrm{E}_{\mathrm{sb}}$ layer could accumulate in that vicinity, raising the possibility that an intense $\mathrm{E}_{\mathrm{sb}}$ layer could be present at low latitudes that could act through the GDI mechanism to produce irregularities that are responsible for $\mathrm{GHz}$ scintillations.

\section{Daytime GHz scintillation association with equator band of $E_{s b}$}

The finding that the $\mathrm{GHz}$ scintillation that occurred at the dip equator (Langkawi) is consistent with the equatorial band of $\mathrm{E}_{\mathrm{sb}}$. This provides evidence that daytime $\mathrm{GHz}$ scintillation at the dip equator is relatively rare. In fact, according to the new interpretation (see "New interpretation"Section), once the $E_{s b}$ is dumped, it will no longer be pushed out of the EEJ region by the $E_{p}$. At the same time, the electric field and $E_{\mathrm{sb}}$ should be able to produce scintillation by GDI.
Since the $\mathrm{E}_{\mathrm{sb}}$ layer is a sheet-like ionization layer with sharp gradients and a small vertical thickness, this layer provides a perfect geometrical configuration of a welldefined ionization gradient located in magnetic fields at the magnetic dip equator. This feature can be used to study the growth process of gradient instability (Reddy and Devasia 1977). Therefore, the region in the vicinity of the EEJ appears to be an ideal "laboratory" to conduct such experiments. The dominant driver of electron drift there is the same as that of the EEJ, the vertical $E_{p}$, and indications are that the presence of $\mathrm{E}_{\mathrm{sb}}$ in that vicinity is controlled by a balance in horizontal transport of $\mathrm{E}_{\mathrm{sb}}$, between the EEJ electric field and the neutral wind, as described in a model by Tsunoda (2008). Hence, we can now say that the GDI would seem to be the source of scintillation during daytime, particularly in the vicinity of dip equator.

\section{Conclusions}

Comprehensive characteristic study of daytime GHz scintillations in the vicinity of the dip equator, for the first time, shows that the occurrence of daytime $\mathrm{GHz}$ scintillation consistent with a scenario in which $\mathrm{E}_{\mathrm{sb}}$ presence is dictated by the Tsunoda model (Tsunoda 2008), and the plasma-density irregularities responsible for $\mathrm{GHz}$ scintillations seem to be produced by GDI.

\section{Highlights}

- Drastic decrease of daytime $\mathrm{GHz}$ scintillation at the dip equator.

- Daytime GHz scintillation in the vicinity of the magnetic dip equator shows seasonal dependence.

- Occurrences of daytime $\mathrm{GHz}$ scintillation over the dip equator are consistent with the presence of $\mathrm{E}_{\mathrm{sb}}$ according to the sporadic $\mathrm{E}$ transport model by Tsunoda (2008).

- The gradient-drift instability appears to be the source mechanism for daytime $\mathrm{GHz}$ scintillation over the dip equator.

\section{Abbreviations}

$E_{p}$ : polarization electric fields; $E_{s b}$ : blanketing sporadic $E_{;}$GDI: gradient-drift instability; l: inclination angle.

\section{Competing interests}

The authors declare that they have no competing interests.

\section{Authors' contributions}

AS carried out the computations and analyzed the data, conducted the main part of analysis, created the figures, and wrote the paper. RT proposed the topic and conceived the study, guided the direction of research, provided the models, interpreted the scientific results, and helped in the production of the manuscript. MA implemented the GISTM project and installed the GPS scintillation monitoring system over Malaysia including UKM and Langkawi stations. MA and $\mathrm{AMH}$ collaborated in the production of the manuscript. All authors read and approved the final manuscript. 


\section{Authors' information}

AS is a young scientist who received her M. Eng in Electronics and Telecommunication from University Technology of Malaysia with honors in 2009. She recently obtained her Ph.D. degree in Electrical, Electronic and Systems Engineering from Universiti Kebangsaan Malaysia (UKM) specializing in the field ionospheric irregularities in equatorial regions where ionospheric scintillation is the most common and severe. She has already had some international collaborations with publications in peer-reviewed journals and conference proceedings. She is the recipient of several research awards, including 2015 Australian Research Fellowship, Malaysian Research Scholarship (2010-2013), Researcher Honorarium, Graduate Student Research Grant, and Graduate Student Travel Support. Currently, she is a Visiting Research Fellow conducting her research at RMIT University, Australia. Aramesh brings together the benefits of observations, data synthesis, and product generation, with a goal to improve the level of services delivered to GNSS users as well as to enhance the potential for developing shared services with other international space weather centers. The long-term goal of her research and academic pursuits are to combine international efforts in providing better space weather prediction services.

RT is a principal scientist at Center for Geospace Studies (CGS), SRI International, Menlo Park, California, who has more than 40 years experience in ionospheric and plasma physics. He is the author of more than 120 scientific publications, which have appeared primarily in the Journal of Geophysical Research and Geophysical Research Letters, as well as in other international peer-reviewed scientific journals. He received his Bachelor's and Master's Degrees in Electrical Engineering from the University of Hawaii in 1964 and 1966. He obtained his Ph. D. degree in Electrical Engineering from Kyoto University in 1996. Accomplishments: First to validate modified two-stream instability as principal source of plasma-density irregularities in E region [Tsunoda 2008], first to use an incoherent-scatter radar for equatorial spread F studies $\Pi$ sunoda et al. 1979], first to demonstrate importance of large-scale wave structure and the eastward neutral wind in development of equatorial plasma bubbles [Tsunoda, 1981, 1983; Tsunoda and White, 1981], developed first successful theory to explain seasonal-longitudinal dependence of equatorial spread $F$ [Tsunoda, 1985], developed a new frequency-agile radar for ionospheric studies [Tsunoda et al., 1995], discovered a new sporadic E layer instability [Cosgrove and Tsunoda, 2002], and demonstrated how electrical coupling of sporadic E layer instability to the Perkins instability enhances the latter [Tsunoda, 2003, 2007; Cosgrove and Tsunoda, 2004]

MA received her B. Eng degree from University of the Ryukyus, Japan, in Electronics and Information Engineering in 1991. She obtained her M. Sc degree from Universiti Kebangsaan Malaysia (UKM) in Electrical, Electronic and Systems Engineering in 1995. In 2004, she was awarded a Ph.D. degree in Electrical Engineering from the University of Leeds, UK, for a work on ionospheric effects on GPS satellite range finding. She works as an engineer at Hitachi Electronics Product in 1991-1996 and as a lecturer in Universiti Kebangsaan Malaysia since 1997. Currently, she is a professor in Electrical, Electronic and Systems Engineering Department and acting as head of Space Science Centre, UKM. Her interest is in ionospheric research and GPS satellite error mitigation. She is a registered professional engineer in Malaysia since 2002 and a member of IEM, Malaysia.

AMH received her B. Eng degree from Universiti Kebangsaan Malaysia in Electrical, Electronic and Systems Engineering in 2000. She obtained her M. Sc degree from University of Duisburg-Essen, Germany, in Information and Communication Engineering in 2004. She was awarded a Ph.D. degree in Electrical Engineering from Universiti Kebangsaan Malaysia majoring in ionospheric response to earthquakes in 2011. Since 2001, she has been working as a lecturer in Universiti Kebangsaan Malaysia and is currently a senior lecturer in the Department of Electrical, Electronic and Systems Engineering, Faculty of Engineering and Built Environment. She is also an associate fellow of Space Science Centre, UKM. Her research interests are in ionosphere research and disaster management.

\section{Acknowledgements}

A. Seif gratefully acknowledges support from the 2015 Endeavour Australian Fellowship. This research was also supported by the Zamalah Research Scholarship awarded to her during her Ph.D. as well as research grant UKM-DPP-2013-046. The authors (AS, MA, AMH) would like to express sincere thanks to the Universiti Kebangsaan Malaysia (UKM) and the Langkawi National Observatory for providing the Langkawi station's data. The research conducted by one of the authors (RTT) was supported by the National Science Foundation under grant ATM-1242815 and the Air Force Office of Scientific Research under contract FA9550-15-C-0018. The data for this paper are available on request (please contact Mardina Abdullah, mardina@eng.ukm.my). One of the authors (A. Seif) would like to thank Dr. Brett Carter for his useful help.

\section{Author details}

${ }^{1}$ Department of Electrical, Electronics and Systems Engineering, Faculty of Engineering and Built Environment, Universiti Kebangsaan Malaysia, 43600 Selangor, Malaysia. ${ }^{2}$ SPACE Research Centre, RMIT University, Melbourne, Victoria, Australia. ${ }^{3}$ Center for Geospace Studies, SRI International, Menlo Park, CA, USA. ${ }^{4}$ Space Science Center (ANGKASA), Selangor, Malaysia.

\section{Received: 3 March 2015 Accepted: 26 October 2015} Published online: 04 November 2015

\section{References}

Alfonsi L, Spogli L, Pezzopane M, Romano V, Zuccheretti E, De Franceschi G, Cabrera MA, Ezquer RG (2013) Comparative analysis of spread-F signature and GPS scintillation occurrences at Tucumán, Argentina. J Geophys Res 118:4483-4502. doi:10.1002/jgra.50378

Alken P, Maus S. (2007) Spatio-temporal characterization of the equatorial electrojet from CHAMP, Ørsted, and SAC-C satellite magnetic measurements. J Geophys Res 112:A09305. doi:10.1029/2007JA012524.

Anderson D, Araujo-Pradere E, Scherliess L (2009) Comparing daytime, equatorial EXB drift velocities and TOPEX/TEC observations associated with the 4-cell, nonmigrating tidal structure. Ann Geophys 27:2861-2867, www.ann-geophys.net/ 27/2861/2009/

Axford WI (1961) Note on a mechanism for the vertical transport of ionization in the ionosphere. Can J Phys 39:1393

Axford WI, Cunnold DM (1966) The wind shear theory of temperate zone sporadic E. Radio Sci 1:191

BaiQui N, LianHuan HU, GuoZhu LI, LiBo LIU, WeiXing WAN (2012) The first time observations of low-latitude ionospheric irregularities by VHF radar in Hainan. Sci China Technol Sci 55:5, http://dx.doi.org/10.1007/s11431-012-4800-2

Basu S, Aarons J, Balsley BB. (1977) on the nature of the electrojet irregularities responsible for daytime VHF scintillations. J Geophys Res 82:5262.

Bhargava BN, Subrahmanyan RV (1964) A study of blanketing sporadic E in the Indian equatorial region. Proc Indiana Acad Sci 60:271

Carter BA, Zhang K, Norman R, Kumar W, Kumar S (2013) On the occurrence of equatorial F-region irregularities during solar minimum using radio occultation measurements. J Geophys Res Space Phys 118:892-904. doi:10.1002/jgra.50089

Chandra H, Rastogi RG (1975) Blanketing sporadic E layer near the magnetic equator. J Geophys Res 80:149. doi:10.1029/JA080i001p00149

Chandrasekhar NP, Arora K, Nagarajan N (2014) Evidence of short spatial variability of the equatorial electrojet at close longitudinal separation. Earth Planets Space 66:110

Chapman S, Raja Rao KS (1965) The H and Z variations along and near the equatorial electrojet in India, Africa and the Pacific. J Atmos Terr Phys 5:559-581

Chatterjee S, Chakrabortyn SK, Majumdar S (2013) Summer time scintillations near the transition zone of the Indian longitude sector. J Atmos Terr Phys 95-96:102-115

Chatterjee S, Chakraborty SK, Veenadhari B, Banola S (2014) A study on ionospheric scintillation near the EIA crest in relation to equatorial electrodynamics. J Geophys Res Space Phys 119:1250-1261. doi:10.1002/ 2013JA019466

Chimonas G, Axford WI (1968) Vertical movement of temperate zone sporadic E layers. J Geophys Res 73:111. doi:10.1029/ JA073i001p00111

Devasia CV (1976) Blanketing sporadic-E characteristics at the equatorial stations Trivandrum and Kodaikanal. Indian J Radio Space Phys 5:217-220

Dubey S, Wahi R, Gwal AK (2006) lonospheric effects on GPS positioning. Adv Space Res 38(11):2478-2484

Ecklund WL, Carter DA, Balsley BB (1981) Gradient drift instability in mid-latitude sporadic E. J Geophys Res 86:858

Fejer BG, Farley DT, Balsley, BB Woodman RF. (1975). Vertical structure of the VHF backscattering region in the equatorial electrojet and the gradient drift instability. Journal of Geophysical Research 80: doi: 10.1029/JA080i010p01313. issn: 0148-0227.

Fejer BG, Kelley MC (1980) lonosphere irregularities. Rev Geophys Space Phys 18:401-454

Fujita M, Ogawa T, Koike K (1978) $1.7 \mathrm{GHz}$ scintillation measurements at midlatitudes using a geostationary satellite beacon. J Atmos Terr Phys 40:963-968 
Gwal AK, Dubey S, Wahi R (2004) A study of L-band scintillations at equatorial latitudes. Adv Space Res 34(9):2092-2095

Hajkowicz LA (1977) Multi-satellite scintillations, spread-F, and sporadic-E over Brisbane-1. J Atmos Terr Phys 39(3):359-365

Hajkowicz LA (1978) Multi-satellite scintillations, spread-F and sporadic-E over Brisbane-2. J Atmos Terr Phys 40(1):99-104

Hajkowicz LA, Minakoshi H (2003) Midlatitude ionospheric scintillation anomaly in the Far East. Ann Geophys 21(2):577-581

Huang YN (1978) lonospheric scintillations at Lunping. J Chinese Inst Eng 1:81-84 Koparkar PV, Rastogi RG, Sastri JH (1989) Daytime equatorial VHF radiowave scintillations and sporadic-E layer. Indian J Radio Space Phys 18:121-124

Kumar S, Kishore A, Ramachandran V (2007) Ionospheric scintillations on $3.925 \mathrm{GHz}$ signal from Intelsat (701) at low latitude in the South Pacific region. Phys Scr 75:258-262. doi:10.1088/0031-8949/75/3/005

Miller KL, Smith LG (1975) Horizontal structure of midlatitude sporadic E layers observed by incoherent scatter radar. Radio Sci 10:271

Miller KL, Smith LG (1978) Incoherent scatter radar observations of irregular structure in mid-latitude sporadic E layers. J Geophys Res 83:3761

Narayanan V, Sau S, Gurubaran S, Shiokawa K, Balan N, Emperumal K, Sripathi S (2014) A statistical study of satellite traces and evolution of equatorial spread F. Earth Planets Space 66:160. doi:10.1186/s40623-014-0160-4

Ogawa T, Suzuki A, Kunitake M (1989) Spatial distribution of mid-latitude sporadic E scintillations in summer daytime. Radio Sci 24(4):527-538

Oyinloye JO (1971) A study of blanketing sporadic E in the equatorial region. Planet Space Sci 19:1131. doi:10.1016/0032-0633(71)90109-7

Patel K, Singh AK, Patel RP, Singh RP (2007) lonospheric scintillations by sporadic-E irregularities over low latitude. Bull Astron Soc India 35:625-630

Patel K, Singh AK, Patel RP, Singh RP (2009) Characteristics of low latitude ionospheric E-region irregularities linked with daytime VHF scintillations measured from Varanasi. J Earth Syst Sci 118(6):721-732

Rangarajan GK, Arora BR (1980) Local time dependence of the seasonal and solar cycle variations in equatorial electrojet field, Indian Institute of geomagnetism, Colaba, Bombay, vol 8. Pergamon Press, Oxford, pp 17-20

Rastogi RG, Mullen J (1981) Intense daytime radio wave scintillations and sporadic E layer near the dip equator. J Geophys Res 86(A1):195-198

Rastogi RG, (1983) Equatorial electrojet and radio scintillations. J Atmos Terr Phys 45:719.

Rastogi RG, Deshpande MR, Murthy BS, Davies K (1977) Daytime satellite radio scintillation and sporadic E near the magnetic equator. Geophys Res Lett 4(3):113-115

Reddy CA, Devasia CV (1973) Formation of blanketing sporadic E layers at the magnetic equator due to horizontal wind shears. Planet Space Sci 21:811. doi:10.1016/0032-0633 (73)90098-6

Reddy CA, Devasia CV (1977) VHF radar observations of gradient instabilities associated with blanketing layers in the equatorial electrojet. J Geophys Res 82(1):125-128

Seif A, Abdullah M, Hasbi AM, Zou Y (2012) Investigation of ionospheric scintillation at UKM station, Malaysia during low solar activity. Acta Astronaut 81:92-101. doi:10.1016/j.actaastro.2012.06.024

Sinno K, Kan M (1980) lonospheric scintillation and fluctuation of Faraday rotation caused by spread-F and sporadic-E over Kokobunji, Japan. J Radio Res Labs 27:53-77

Somayajulu YV, Garg SC, Dabas RS, Singh L, Tyagi TR, Lokanadham B, Ramakrishan S, Navneeth $G$ (1984) Multistation study of nighttime scintillations in low latitudes: evidence of control by equatorial F-region irregularities. Radio Sci 19:707-718

Tanna H J, Karia SP, Pathak KN (2013) A study of L band scintillations during the initial phase of rising solar activity at an Indian low latitude station. J Adv Space Res. 1-10. doi:10.1016/j.asr.2013.03.022.

Tarpley, JD (1973) Seasonal movement of the Sq current foci and related effects in the equatorial electrojet. J Atmos Terr Phys 35:1063-1071.

Tong YU, Mathews JD, Yang WP (1988) An upper E region quarter diurnal tide at Arecibo? J Geophys Res 93:10047

Tsunoda RT (2008) On blanketing sporadic E and polarization effects near the equatorial electrojet. J Geophys Res 113:1-10. doi:10.1029/2008JA013158, A09304

Van Dierendonck AJ, Klobuchar J, Hua Q (1993) lonospheric scintillation monitoring using commercial single frequency C/A code receivers, Paper presented at the Sixth International Technical Meeting (ION GPS-93). Satell. Div., Inst. of Navig, Salt Lake City

Whitehead JD (1966) Mixtures of ions in the wind shear theory of sporadic E. Radio Sci 1:198-203
Whitehead JD (1969) The formation of sporadic E layer in the temperate zones. J Atmos Terr Phys 20:49-58

Whitehead JD (1989) Recent work on mid-latitude and equatorial sporadic-E. J Atmos Terr Phys 51(5):401-424

Whitehead, J D (1970) Production and prediction of sporadic E, Reviews of Geophysics 8:65.

Wu DL, Ao CO, Hajj GA, Juarez MDLT, Mannucci AJ (2005) Sporadic E morphology from GPS-CHAMP radio occultation. J Geophys Res 110:A01306

Yacob A (1966) Seasonal parameters of the equatorial eleotrojet at different longitudinal zones. J Atmos Terr Phys 28:581-597, Pergamon Press Ltd. Printed in Northern Ireland

Zeng Z, Sokolovskiy S (2010) Effect of sporadic E clouds on GPS radio occultation signals. Geophys Res Lett 37:1-5. doi:10.1029/2010GL044561

Zou YH (2011) lonospheric scintillations at Guilin detected by GPS ground based and radio occultation observations. Adv Space Res 47:945-965. doi:10.1016/ j.asr.2010.11.016

Zou YH, Wang DL (2009) A study of GPS ionospheric scintillations observed at Guilin. J Atmos Terr Phys 71(17-18):1948-1958

\section{Submit your manuscript to a SpringerOpen ${ }^{\odot}$ journal and benefit from:}

- Convenient online submission

Rigorous peer review

- Immediate publication on acceptance

- Open access: articles freely available online

- High visibility within the field

- Retaining the copyright to your article

Submit your next manuscript at springeropen.com 